\title{
The Re-Emerging Role of Iron in Infection and Immunity
}

\author{
Mawieh Hamad ${ }^{1,2 *}$ and Khuloud Bajbouj ${ }^{2}$ \\ ${ }^{1}$ Department of Medical Laboratory Sciences \\ ${ }^{2}$ Sharjah Institute for Medical Research, University of Sharjah, Sharjah, UAE
}

\begin{abstract}
Much has been achieved over the past three decades in the quest to understand iron homeostasis and the mechanisms governing it. Several proteins including hepcidin, ferroprtin, transferrin receptors, and ferritin have been identified as key players in iron metabolism and homeostasis. This has provided for a thorough revisiting of the role of iron in various disease states including cancer, cardiovascular diseases, and susceptibility to infection to name few. Regarding the later, although the idea that iron is essential for microbial pathogenesis has been known for a long time, knowledge regarding key mechanisms employed by pathogens to extract iron and counter mechanisms employed by the immune system to sequester iron has expanded in a significant way. Furthermore, there is renewed interest in the role of iron in immunity and the extent and ramifications of the reciprocal effects of either on the other. This mini-review starts by introducing the reader to the basics of iron metabolism and goes on to briefly, but non-exhaustively, recount the epic fight for iron between pathogen and host.
\end{abstract}

\section{Background}

The discovery that iron regulates ferritin mRNA translation [1] and the subsequent identification of several key genes and proteins involved in iron metabolism has marked the start of a new age for iron biology. Owing to its unique electrochemical properties, iron functions as a redox active cofactor in a wide array of biological processes. Cellular and secreted enzymes and proteins that use iron as a cofactor are involved in all aspects of cell metabolism including cellular respiration, DNA replication, gene expression, cell cycling, cell signaling and apoptosis among others. Iron also serves as a sensor of cellular redox status; that is, iron-based sensors use iron-containing molecules (heme, $\mathrm{Fe}-\mathrm{S}$ clusters, mononuclear iron, etc.) as switches to regulate protein activity in response to changes in cellular redox balance [2]. Hence, iron deficiency associates with a wide range of adverse health consequences including anemia and compromised immunity. Excess iron on the other hand, which under aerobic conditions drives the propagation and generation of oxygen and hydroxyl free radicals, associates with compromised immunity, cancer, cardiovascular disease, and inflammation among other disease states. Renewed interest in iron biology in recent years has deepened our understanding of how iron metabolism is regulated and has also provided for a more systematic approach to address the role of disrupted iron homeostasis in disease.

Iron homeostasis: the basics: Mammalian systems have evolved intricate mechanisms to maintain iron homeostasis and to tightly regulate iron absorption and release (Figure 1). Ferroportin (FPN) channels on enterocytes and macrophages efflux intracellular ferrous iron into the circulation, first to be instantaneously oxidized by ceruloplasmin and/or hephaestin and then loaded onto transferrin [3]. The ferric-transferrin complex is subsequently delivered to target cells by endocytosis through transferrin receptor 1 (TfR1; CD71). FPN expression is negatively impacted by the hepatocyte-derived peptide hormone hepcidin, which triggers the internalization, phosphorylation and degradation of FPN [4]. Increased demand for iron therefore downregulates hepcidin synthesis by upregulating the transcription of hypoxia inducible factor $1 \alpha$ (HIF-1 $\alpha$ ) [5] and the growth differentiation factor 15 (GDF15) [6] among other mechanism [7]. In contrast, ferric- transferrin complex in excess induces the disengagement of the human hemochomatosis (HFE) protein from TfR1 and its engagement with $\mathrm{TfR} 2$, an event that upregulates hepcidin synthesis [4,8]. Inflammatory cytokines (IL-6 and IL-1) [9,10] and innate immunity receptors (toll-like receptor 4; TLR-4) [11] can also upregulate hepcidin gene expression as means of intracellular iron sequestration during infection.

In addition to changing demand and inflammation, mounting evidence suggest that iron homeostasis can be influenced by estrogen

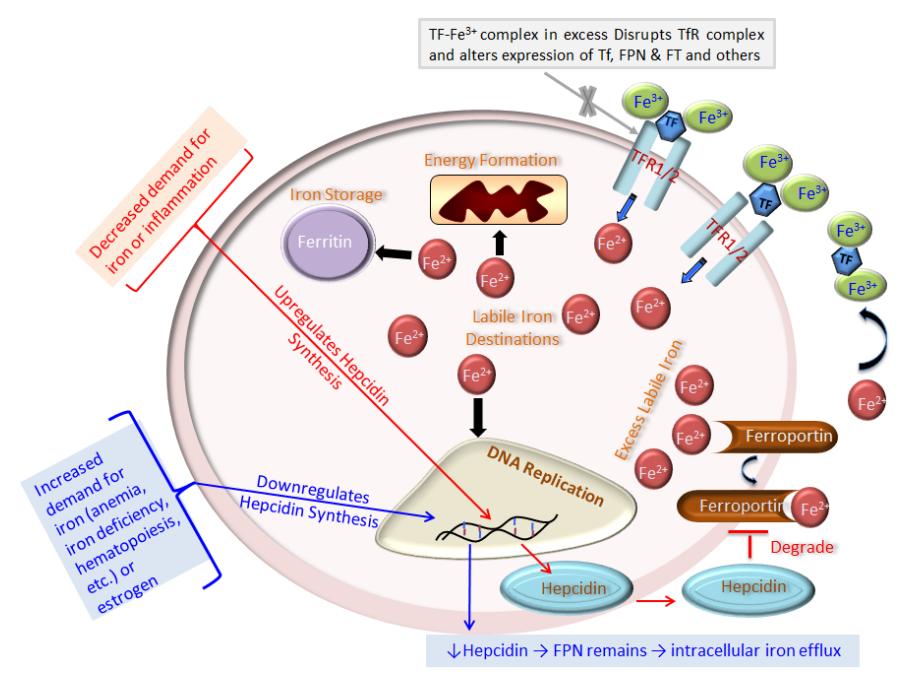

Figure 1. Basic aspects of iron metabolism regulation in body cells. TF, transferrin; TFR, transferrin receptor; FPN, ferroportin.

Correspondence to: Dr. Mawieh Hamad, Department of Medical Laboratory Sciences, University of Sharjah, Sharjah, UAE, PO Box 27272, Tel: 009715057553; E-mail: mabdelhaq@sharjah.ac.ae

Key words: Iron, Hepcidin, Ferroportin, Estrogen, Infection, Immunity

Received: October 14, 2016; Accepted: October 27, 2016; Published: October 29,2016 
(17- $\beta$ estradiol, E2). Ovariectomy in rodents associate with decreased serum iron, iron binding capacity, and iron response protein-1 binding activity [12]. In contrast, oral contraceptives in humans [13] and E2 treatment in ovariectomized mice $[14,15]$ associate with increased levels of serum iron and total iron-binding capacity [16]. Additionally, the expression of several proteins involved in iron metabolism increases under the influence of E2 [15]. The exact mechanism as to how estrogen enhances serum iron availability is not well understood. However, recent in vitro work has suggested that $\mathrm{E} 2$ treatment reduces hepcidin synthesis in hepatocyte-derived cells (HepG2) [16], as well as breast (MCF-7) and ovarian (SKOV-3) adenocarcinomas [17]. In HepG2, the ability of E2 to downregulate hepcidin synthesis was shown to be dependent on E2 binding to estrogen response elements (EREs) in the hepcidin gene [16], an effect which can be reversed by ICI 182780 (an E2 antagonist). E2 treatment in vitro was also shown to enhance the expression of HIF-1a in the ovarian cancer cell lines ES-2 and SKOV3 by activating the serine/threonine kinase signaling pathway [18]. Although HIF-1a induces the expression of the neovascularization angiogenic protein VEGF [19] which enhances cancer development and progression, HIF-1 $\alpha$ also downregulates hepcidin synthesis [20], hence its role in intracellular iron modulation. E2 has also been shown to inhibit the release of several cytokines including IL-1, IL-6, IL-22, TGF- $\beta 1$, and TLR5, at least some of which (IL-1 and IL-6) are known to upregulate hepcidin synthesis [21]. By downregulating hepcidin synthesis and upregulating FPN expression, E2 treatment was recently reported to enhance labile intracellular iron efflux in MCF-7 and SKOV-3 cells [22] (Figure 2).

Infection, immunity and the fight for iron: Owing to its significant redox potential, iron availability is essential for both pathogen and host immunity. Iron enhances the growth and virulence of pathogens; at the same time, it is essential for the activation and proliferation of immune cells [23]. Therefore, iron deficiency negatively affects the pathogen and the host, albeit more so in the case of host immunity. This partially explains the well-documented observation that patients with iron deficiency exhibit increased susceptibility to infection. Iron overload also seems to favor the pathogen, as it tends to suppress host immunity [23]. At homeostatic conditions however, with the primary phase of microbial infections ensues a bitter fight for iron. Immune cells fight to sequester iron by upregulating the expression of IL-1 and IL- 6 among other mediators that enhance hepcidin synthesis and block intracellular iron efflux [22]. By doing so, innate immunity deprives the pathogen of badly-needed iron and arrests its growth and dissemination [24]. To counter such an inflammation-dependent iron sequestration response, pathogens have evolved an exquisite ability to chelate iron from heme and other molecules by expressing ferric

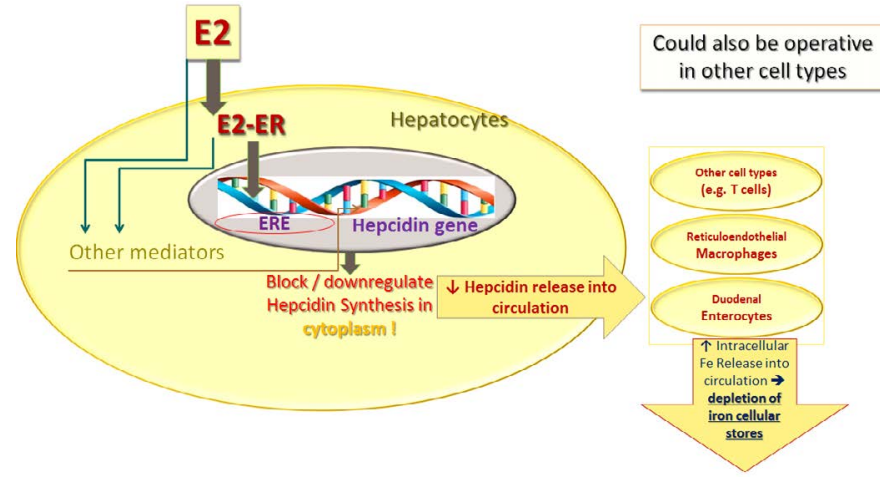

Figure 2. A proposed mechanism to explain how estrogen could be involved in regulating iron homeostasis. E2, estrogen; ER, estrogen receptor; ERE, estrogen response elements. reductase [25] and iron-chelating siderophores and hemophores (e.g. desferricoprogen, desferrichrome, desferrirubin, and desferrichrysin) [26]. Therefore, high-affinity iron scavenging by siderophores is a well-recognized virulence determinant in microbial pathogenesis in mammals [27]. High pathogenicity islands in pathogenic strains of Yersinia and several members of the enterobacteriaceae use the iron acquisition molecule yersiniabactin to chelate iron from host proteins [28]. Increased synthesis of proteins involved in iron-uptake and utilization has been documented in human blood cultures of methicillin-resistant Staphylococcus aureus [29]. Better protection against mucormycosis was achieved in immunocompromised hosts by using the non-siderophoric deferasirox in place of the siderophoric iron chelator deferoxamine [30]. Susceptibility of liver transplant patients to invasive aspergillosis, cryptococcosis, and zygomycosis has been shown to correlate with iron overload [31]. Use of deferasirox in conjunction with liposomal amphotericin B has also been shown to improve treatment outcome by increasing survival and reducing fungal burden in mice with invasive pulmonary aspergillosis (IPA) $[30,32]$. Proteomic analysis has shown that the expression of proteins involved in iron acquisition by the marine bacterium Vibrio vulnificus significantly increases during the early-middle growth phase of the pathogen [33]. Secreted glutathione-dependent ferric reductase activity in Histoplasma capsulatum was shown to aid in iron acquisition and sequestration and hence pathogenesis over a broad $\mathrm{pH}$ range [34].

Iron acquisition systems in pathogens not only help the pathogen to grow and become more virulent, but also suppress host immunity. Several gastrointestinal microbes have been reported to sequester iron from the host in order to disrupt the activity of phagocytes that require iron for the production of hydroxyl radicals and superoxide reactions as means of microbial killing [35]. Furthermore, siderophores like desferrioxamine (DFO), desferrichrome (DFC), desferriaerobactin (DFAB) and desferrienterobactin (DFEA) enhance the virulence of pathogens [36-38] by helping the pathogen acquire iron and induce immunosuppression in the host [37].

Notwithstanding the fact that iron is critical for immune cell proliferation and activation, iron overload resulting from dietary excess, abnormal hemolysis or inherited disorders often associates with immunosuppression and increased susceptibility to infection [39, 4042]. The immunosuppressive effects of iron on immunity manifests in a whole host of innate and adaptive responses. In that, increased iron concentration in HepG2 cells infected with C. trachomatis show reduced indoleamine 2,3-dioxygenase (IDO; the enzyme that catalyses tryptophan metabolism) expression and diminished potential to inhibit the infection through IFN- $\gamma$ [43]. Iron overload in liver transplant recipients has been reported to minimize the need for immunosuppressive therapy [44]. Upregulated expression of genes involved in iron metabolism, increased serum levels of hepcidin and ferritin, and hepatocyte iron deposition has been observed in such patients [44]. This suggests that endogenous iron may exert immunosuppressive effects at a level high enough to allow for graft survival without the need for immunosuppressive therapy. Ironoverloaded mice with experimental candidiasis fail to mount strong candidacidal responses; neutrophils and macrophages in such mice show reduced ability to produce nitric oxide and IL-12 [45]. However, treatment with deferoxamine helps to resolve the infection, restore phagocytic function and re-direct Th differentiation from a nonprotective (IL-4 producer) to a protective (IFN- $\gamma$ producer) phenotype [45].

\section{More on the relationship between iron and immunity}

The identification of key genes involved in iron regulation and 
homeostasis in various types of immune cells including $\mathrm{T}$ cells and macrophages has expanded our knowledge of the relationship between immunity and iron. Now, it is becoming clear that both iron and the immune response differentially and reciprocally interact with one another. That is, immunity plays a considerable role in managing intracellular iron and in responding measurably to changing levels of systemic iron. On the other hand, iron and iron regulatory proteins modulate the immune response at different levels and in different contexts. Several studies have shown that immune cells do participate in iron homeostasis in general. That said, much remains to be done to fully appreciate the extent of such interactions and their effects on the immune response and on iron homeostasis. This notwithstanding, the short discussion below is only meant to introduce the reader to this emerging area in immunological and iron biology research. Lactoferrin (an iron binding, transport and storage protein)exerts significant immune-regulatory effects on Th1/Th2 cell activities [46]. Transferrin in macrophages and $\mathrm{T}$ lymphocytes [47] has proven essential for early $\mathrm{T}$-cell differentiation [48]. Transferrin receptor 1 (TfR1) has been shown to be critical for DNA synthesis and cell division in T lymphocytes [49]. Both macrophages and T lymphocytes have been shown to express significant levels of the iron storing protein ferritin (FT) [50-51]. Expression of Nramp1 (SCLA11) and Nramp2/ DMT-1 on late phagosome was reported to enhance resistance to intracellular pathogens [52-53]. The intracellular iron efflux protein FPN1 (FPNIREG1) was shown to downregulate during microbial infections in a TLR4-dependent manner [54]. Hemochromatosis (iron overload) was reported to often associate with disrupted hepcidin gene expression [55]; hepcidin is an antimicrobial peptide and a key regulator of iron homeostasis [56]. The ability of IL-1 and IL-6 to enhance hepcidin synthesis and downregulate FPN expression seems to be instrumental in depriving pathogens of badly-needed iron during infection $[21,57]$. Targeted disruption of heme-oxygenase 1 (Hmox1; the enzyme that neutralizes iron) in mice was reported to induce iron overload [58]; high CD4/CD8 ratios with activated CD4 ${ }^{+}$ cells were documented in these mice. Lastly, MHC-class I deficient mice tend to develop hepatic iron overload [59] and show reduced protection against viral infections due to their inability to present viral peptides to host antigen presenting cells (APCs) [60].

\section{Competing Interests}

The authors declare that they have no competing interests.

\section{Authors Contributions}

$\mathrm{MH}$ wrote and edited the manuscript and designed figure 2, KB helped to assemble the required references, prepared figure 1 , and reviewed the manuscript. Both authors have read and approved the final manuscript.

\section{Acknowledgments}

This work was supported by research grants (i) UOS-MH15010505100-P, College of Graduate Studies and Research, University of Sharjah, Sharjah, UAE and (ii)AJF2016-64, Al-Jalila Foundation, Dubai, UAE in addition to a research group operational budget, the Sharjah Institute for Medical Research, University of Sharjah, Sharjah, UAE.

\section{References}

1. Aziz N, Munro HN (1987) Iron regulates ferritin mRNA translation through a segment of its 5' untranslated region. Proc Natl Acad Sci U S A 84: 8478-8482. [Crossref]

2. Outten FW, Theil EC (2009) Iron-based redox switches in biology. Antioxid Redox
Signal 11: 1029-1046. [Crossref]

3. Anderson GJ, Wang F (2012) Essential but toxic: controlling the flux of iron in the body. Clin Exp Pharmacol Physiol 39: 719-724. [Crossref]

4. Nemeth E, Tuttle MS, Powelson J, Vaughn MB, Donovan A, et al. (2004) Hepcidin regulates cellular iron efflux by binding to ferroportin and inducing its internalization. Science 306: 2090-2093. [Crossref]

5. Peyssonnaux C, Zinkernagel AS, Schuepbach RA, Rankin E, Vaulont S, et al. (2007) Regulation of iron homeostasis by the hypoxia-inducible transcription factors (HIFs). $J$ Clin Invest 117: 1926-1932. [Crossref]

6. Tanno T, Bhanu NV, Oneal PA, et al. (2007) High levels of GDF15 in thalassemia suppress expression of the iron regulatory protein hepcidin. Nat Med 3: 1096-1101. [Crossref]

7. Silvestri L, Pagani A, Nai A, et al. (2009) The serine protease matriptase-2 (TMPRSS6) inhibits hepcidin activation by cleaving membrane hemojuvelin. Cell Metab 8: 502511. [Crossref]

8. Schmidt PJ, Toran PT, Giannetti AM, et al. (2008) The transferrin receptor modulate Hfe-dependent regulation of hepcidin expression. Cell Metab 7: 205-214. [Crossref]

9. Brock JH, Halliday JW, Powell LW. (1994) Iron metabolism in health and disease, London, W.B. Saunders Company Ltd.

10. Kühn LC. (1996) Control of cellular iron transport and storage at the molecular level. In: Hallberg LA, et al., eds. Iron nutrition in health and disease. p. 17-29. London, John Libbey \& Company.

11. Andrews NC (2008) Forging a field: the golden age of iron biology. Blood 112: 219230. [Crossref]

12. Mattace Raso G, Irace C, Esposito E, et al. (2009) Ovariectomy and estrogen treatment modulate iron metabolism in rat adipose tissue. Biochemical Pharmacology 78: 10011007. [Crossref]

13. Campesi I, Sanna M, Zinellu A, Carru C, Rubattu L, et al. (2012) Oral contraceptives modify DNA methylation and monocyte-derived macrophage function. Biol Sex Differ 3: 4. [Crossref]

14. Ulas M, Cay M (2011) Effects of $17 \hat{\mathrm{I}}^{2}$-estradiol and vitamin E treatments on blood trace element and antioxidant enzyme levels in ovariectomized rats. Biol Trace Elem Res 139: 347-355. [Crossref]

15. Stuckey R, Aldridge T, Lim FL, et al. (2006) Induction of iron homeostasis genes during estrogen-induced uterine growth and differentiation. Molecular and Cellular Endocrinology 253: 22-29. [Crossref]

16. Yang Q, Jian J, Katz S, Abramson SB, Huang X (2012) 17 $\hat{\mathrm{I}}^{2}$-Estradiol inhibits iron hormone hepcidin through an estrogen responsive element half-site. Endocrinology 153: 3170-3178. [Crossref]

17. Hou Y, Zhang S, Wang L, et al. (2012) Estrogen regulates iron homeostasis through governing hepatic hepcidin expression via an estrogen response element. Genetics 511: 398-403. [Crossref]

18. Hua K, Din J, Cao Q, et al. (2009) Estrogen and progestin regulate HIF-1alpha expression in ovarian cancer cell lines via the activation of Akt signaling transduction pathway. Oncology Report 21: 893-898. [Crossref]

19. Kazi AA, Molitoris KH, Koos RD. (2009) Estrogen rapidly activates the PI3K/AKT pathway and hypoxia-inducible factor 1 and induces vascular endothelial growth factor A expression in luminal epithelial cells of the rat uterus. Biol Reprod 81: 378-387. [Crossref]

20. De Francesco EM, Lappano R, Santolla MF, Marsico S, Caruso A, Maggiolini M (2013) HIF-1a/GPER signaling mediates the expression of VEGF induced by hypoxia in breast cancer associated fibroblasts (CAFs). Breast Cancer Res 15: R64. [Crossref]

21. Lee P, Peng H, Gelbart T, Wang L, Beutler E (2005) Regulation of hepcidin transcription by interleukin-1 and interleukin-6. Proc Natl Acad Sci U S A 102: 1906-1910. [Crossref]

22. Shafarin J, Bajbouj K, El-Serafy A, Sandeep D, Hamad M (2016). Estrogen-dependent downregulation of hepcidin synthesis induces intracellular iron efflux in cancer cells in vitro. Biol Med 8: 6-14 (In Press).

23. Marx JJ (2002) Iron and infection: competition between host and microbes for a precious element. Best Practice in Research and Clinical Haematology 15: 411-426.

24. Ganz T (2006) Hepcidin--a peptide hormone at the interface of innate immunity and iron metabolism. Curr Top Microbiol Immunol 306: 183-198. [Crossref]

25. Zarnowski R, Cooper KG, Brunold LS, Calaycay J, Woods JP (2008) Histoplasma 
capsulatum secreted gamma-glutamyltransferase reduces iron by generating an efficient ferric reductant. Molecular Microbiology 70: 352-368. [Crossref]

26. Jones AM, Wildermuth MC (2011) The phytopathogen Pseudomonas syringae pv. tomato DC3000 has three high-affinity iron-scavenging systems functional under iron limitation conditions but dispensable for pathogenesis. Journal of Bacteriology 193: 2767-2775

27. Malachowa N, DeLeo FR (2011) Staphylococcus aureus survival in human blood Virulence 2: 567-569. [Crossref]

28. Miyamoto K, Kosakai K, Ikebayashi S, Tsuchiya T, et al. (2009) Proteomic analysis of Vibrio vulnificus M2799 grown under iron-repleted and iron-depleted conditions. Microbial Pathogens 46:171-177. [Crossref]

29. Malachowa N, DeLeo FR (2011) Staphylococcus aureus survival in human blood. Virulence 2: 567-569. [Crossref]

30. Ibrahim AS, Spellberg B, Edwards J (2008) Iron acquisition: a novel perspective on mucormycosis pathogenesis and treatment. Current Opinion in Infectious Diseases 21 : $620-625$.

31. Singh N, Sun HY (2008) Iron overload and unique susceptibility of liver transplan recipients to disseminated disease due to opportunistic pathogens. Liver Transplantation 14: 1249-1255. [Crossref]

32. Ibrahim AS, Gebremariam T, French SW, Edwards JE, Spellberg B (2010) The iron chelator deferasirox enhances liposomal amphotericin B efficacy in treating murine invasive pulmonary aspergillosis. Journal of Antimicrobial Chemotherapy 65: 289292. [Crossref]

33. Miyamoto K, Kosakai K, Ikebayashi S, Tsuchiya T, Yamamoto S, et al. (2009) Proteomic analysis of Vibrio vulnificus M2799 grown under iron-repleted and irondepleted conditions. Microb Pathog 46: 171-177. [Crossref]

34. Zarnowski R, Cooper KG, Brunold LS, Calaycay J, Woods JP (2008) Histoplasma capsulatum secreted gamma-glutamyltransferase reduces iron by generating an efficient ferric reductant. Mol Microbiol 70: 352-368. [Crossref]

35. Markel TA, Crisostomo PR, Wang M, Herring CM, Meldrum KK, et al. (2007) The struggle for iron: gastrointestinal microbes modulate the host immune response during infection. J Leukoc Biol 81: 393-400. [Crossref]

36. Keqin Hua, Jingxin Din, Qi Cao, Weiwei Feng, Ying Zhang, et al. (2009) Estrogen and progestin regulate HIF-1 expression in ovarian cancer cell lines via the activation of Akt signaling transduction pathway. Oncology Reports 21: 893-898. [Crossref]

37. Autenrieth I, Hantke K, Heesemann J (1991) Immunosuppression of the host and delivery of iron to the pathogen: a possible dual role of siderophores in the pathogenesis of microbial infections? Med Microbiol Immunol 180: 135-141. [Crossref]

38. Finkelstein RA, Yancey RJ (1981) Effect of siderophores on virulence of Neisseria gonorrhoeae. Infect Immun 32: 609-613. [Crossref]

39. Gangaidzo IT, Moyo VM, Mvundura E, Aggrey G, Murphree NL, et al. (2001) Association of pulmonary tuberculosis with increased dietary iron. $J$ Infect Dis 184 : 936-939. [Crossref]

40. Moyo VM, Gangaidzo IT, Gordeuk VR, Kiire CF, Macphail AP (1997) Tuberculosis and iron overload in Africa: a review. Cent Afr J Med 43: 334-339. [Crossref]

41. Magnus SA, Hambleton IR, Moosdeen F, Serjeant GR (1999) Recurrent infections in homozygous sickle cell disease. Arch Dis Child 80: 537-541. [Crossref]

42. Wanachiwanawin W (2000) Infections in E-beta thalassemia. J Pediatr Hematol Oncol 22: 581-587. [Crossref]
43. Krausse-Opatz B, Wittkop U, Gutzki FM (2009) Free iron ions decrease indoleamine 2,3-dioxygenase expression and reduce IFNgamma-induced inhibition of Chlamydia trachomatis infection. Microbial Pathogens 46: 289-297. [Crossref]

44. Bohne F, Martínez-Llordella M, Lozano JJ (2012) Intra-graft expression of genes involved in iron homeostasis predicts the development of operational tolerance in human liver transplantation. Journal of Clinical Investigations 122: 368-382. [Crossref]

45. Mencacci A, Cenci E, Boelaert JR, Bucci P, Mosci P, et al. (1997) Iron overload alters innate and Thelper cell responses to Candida albicans in mice. J Infect Dis 175: 14671476. [Crossref]

46. Fischer R, Debbabi H, Dubarry M, Boyaka P, Tomé D (2006) Regulation of physiological and pathological Th1 and Th2 responses by lactoferrin. Biochem Cell Biol 84: 303-311. [Crossref]

47. Nishiya K, Chiao JW, De Sousa M (1980) Iron binding proteins in selected human peripheral blood cell sets: immunofluorescence. Br J Haematol 46: 235-245. [Crossref]

48. Macedo MF, de Sousa M, Ned RM, Mascarenhas C, Andrews NC, et al. (2004) Transferrin is required for early T-cell differentiation. Immunology 112: 543-549. [Crossref]

49. Neckers LM, Cossman J (1983) Transferrin receptor induction in mitogen-stimulated human T lymphocytes is required for DNA synthesis and cell division and is regulated by interleukin 2. Proc Natl Acad Sci USA 80: 3494-3498. [Crossref]

50. Dörner MH, Silverstone A, Nishiya K, de Sostoa A, Munn G, et al. (1980) Ferritin synthesis by human T lymphocytes. Science 209: 1019-1021. [Crossref]

51. Vezzoni P, Levi S, Gabri E, Pozzi MR, Spinazze S, et al. (1986) Ferritins in malignant and non-malignant lymphoid cells. Br J Haematol 62: 105-110. [Crossref]

52. Vidal S, Gros P, Skamene E (1995) Natural resistance to infection with intracellula parasites: molecular genetics identifies Nramp1 as the Bcg/Ity / Lsh locus. J Leukoc Biol 58: 382-390.

53. Jabado N, Cuellar-Mata P, Grinstein S, Gros P (2003) Iron chelators modulate the fusogenic properties of Salmonella-containing phagosomes. Proc Natl Acad Sci U S A 100: 6127-6132. [Crossref]

54. Peyssonnaux C, Zinkernagel AS, Datta V, Lauth X, Johnson RS, et al. (2006) TLR4dependent hepcidin expression by myeloid cells in response to bacterial pathogens. Blood 107: 3727-3732. [Crossref]

55. Lesbordes-Brion JC, Viatte L, Bennoun M, Lou DQ, Ramey G, et al. (2006) Targeted disruption of the hepcidin 1 gene results in severe hemochromatosis. Blood 108: 14021405. [Crossref]

56. Ganz T (2003) Hepcidin, a key regulator of iron metabolism and mediator of anemia of inflammation. Blood 102: 783-788. [Crossref]

57. Nemeth E, Rivera S, Gabayan V, Keller C, Taudorf S, et al. (2004) IL-6 mediates hypoferremia of inflammation by inducing the synthesis of the iron regulatory hormone hepcidin. J Clin Invest 113: 1271-1276. [Crossref]

58. Poss KD, Tonegawa $S$ (1997) Heme oxygenase 1 is required for mammalian iron reutilization. Proc Natl Acad Sci U S A 94: 10919-10924. [Crossref]

59. Cardoso EM, Macedo MG, Rohrlich P, Ribeiro E, Silva MT, et al. (2002) Increased hepatic iron in mice lacking classical MHC class I molecules. Blood 100: 4239-4241. [Crossref]

60. Doherty DG, O'Farrelly C (2000) Innate and adaptive lymphoid cells in the human liver. Immunol Rev 174: 5-20. [Crossref]

Copyright: (C2016 Hamad M. This is an open-access article distributed under the terms of the Creative Commons Attribution License, which permits unrestricted use, distribution, and reproduction in any medium, provided the original author and source are credited. 